\title{
HYPOGLYCEMIC ACTIVITY OF A NOVEL POLYHERBAL FORMULATION IN STREPTOZOTOCIN-INDUCED DIABETIC RATS: A THERAPEUTIC STUDY
}

\author{
PULAK MAJUMDER ${ }^{1 *}$, PARIDHAVI M ${ }^{2}$ \\ ${ }^{1}$ Department of CRD, PRIST University, Thanjavur, Tamil Nadu, India. ${ }^{2}$ Department of Pharmacognosy, Rajiv Gandhi Institute of Pharmacy, \\ Trikaripur, Kerala, India. Email: pulak2007@gmail.com
}

Received: 29 September 2018, Revised and Accepted: 26 November 2018

\section{ABSTRACT}

Objective: The concept of the synergistic effect of poly-herbalism was as old as medicine history. Present novel polyherbal formulation (PHF) composed of five different herbs. The present investigation aimed to evaluate the synergistic therapeutic hypoglycemic potential of PHF against streptozotocin (STZ) (60 mg/kg b.w, ip)-induced diabetic rats.

Methods: For this therapeutic study, the dose was framed orally once a day to the test objects after STZ dosing at $500 \mathrm{mg} / \mathrm{kg} / 5 \mathrm{ml} \mathrm{dosage} \mathrm{levels} \mathrm{for}$ 21 days. The transformation of body weight and blood glucose level was examined, and the histopathological changes of beta cells of the pancreas, cellular architectures of liver and kidney were also perceived after scarification of the objects.

Results: The outcomes were compared to that of glibenclamide $(5 \mathrm{mg} / \mathrm{kg}$ ) treated group. Declines of body weight and blood glucose levels were perceived in STZ-induced diabetic animals very significantly $(p<0.01$ or $p<0.05)$. However, these diabetic changes were significantly $(p<0.01$ or $p<0.05)$ decreased in PHF-dosing groups revealed more encouraging effects compared to that of glibenclamide. In the other hand, various liver function and enzymes test (creatinine, urea, total bilirubin, total albumin, alkaline phosphatase, gamma-glutamyl transferase, aspartate transaminases, and alanine transaminases) and lipid profile (total cholesterol, triglycerides, high-density lipoprotein cholesterol, total protein, low-density lipoprotein [LDL], and very LDL) studies strongly indicate the potential action of this novel formulation.

Conclusions: It is deliberated that PHF has the favorable effect to normalize the blood glucose levels, and also rejuvenation and reproduction of beta cells lead a better futuristic ant diabetic therapy for diabetic management.

Key words: Polyherbal formulation, Streptozotocin, Glucose, Pancreas, Histopathology, Lipid profile.

(C) 2019 The Authors. Published by Innovare Academic Sciences Pvt Ltd. This is an open access article under the CC BY license (http://creativecommons. org/licenses/by/4. 0/) DOI: http://dx.doi.org/10.22159/ajpcr.2019.v12i3.29969

\section{INTRODUCTION}

High blood sugar generally termed as hyperglycemia. It is a condition of abnormally high blood glucose level in the blood characterized by the sign of diabetes and pre-diabetes conditions. Diabetes is a chronic metabolic disorder characterized by hyperglycemia due to inadequate insulin-making or non-appropriate response by cell or both. It obstructs directly in the metabolism of macronutrients. Patients with high blood sugar will characteristically experience polyuria, polydipsia, and polyphagia. Categories of diabetes are referred to as type 1 and type 2 which is non-insulin-dependent diabetes, or juvenile onset and adultonset diabetes. Hyperglycemia indications to various diseases such as cardiovascular, hepatic, vision, dental, nerve, and foot ulcer. Around $6 \%$ world population currently suffering from this disorder and it also likely to be changing its dynamics frequently as especially in developing nations [1]. There is a rough estimate say, near about 36 million world populations are undiagnosed of this rapidly growing miserable problem. As per the IDF report, China, India, and the USA will go to host the world $80 \%$ total diabetic population on 2030 [2]. Treatment of various metabolic disorders by poly-herbalism has been recognized in ancient documents like "Sarangdhar Samhita" dated in 1300 A.D. The presence of various phytoconstituents leads to the significant therapeutic efficacy of herbal medicines further potentiated when formulated together with compatible herbals in formulations. It is evident that a better therapeutic effect can be reached with multi-constituent formulations. Combination of herbals may act on multiple targets at the same time to provide a thorough relief [3]. Multi-herbal combination therapy can achieve greater hypoglycemia than monotherapy and can also enhance the safety and tolerability of pharmacotherapy. The plant parts, namely, Cassia auriculata L. [4,5], Mangifera indica [6,7], Ficus banghalensis [8,9], Cinnamomum tamala [10,11], and Trichosanthes diocia [12,13], are abundantly found throughout the Indian subcontinent and scientifically proven for their moderate hypoglycemic potentials and other pharmacological actions. However, the synergistic potential of those herbs on hyperglycemia in the form of the polyherbal formulation (PHF) has not been investigated till date. Hence, the present investigation aimed to evaluate the synergistic therapeutic hypoglycemic potential of PHF against experimentally induced diabetic rat models in vivo.

\section{METHODS}

\section{Chemicals used}

Various experimental chemicals were procured from multiple sources, vis. Streptozotocin (STZ), analytical grade laboratory reagents and chemicals from HiMedia Laboratories, Mumbai, India, SD Fine Chem, Bengaluru, respectively, and Commercial reagent kits obtained from Karnataka fine Chem Ltd., Bengaluru.

\section{Collection of the plant}

Parts of the plants, namely C. auriculata, C. tamala, Ficus benghalensis, M. indica, and Trichosanthes dioica were collected from in an around Kerala state and authenticated. Each plant specimen voucher was deposited in the Department of Pharmacognosy, Rajiv Gandhi Institute of Pharmacy, Trikaripur, India, for future reference. The respective voucher numbers were given for each herb as shown in Table 1.

Extraction of plant material and extract preparation All the procured parts of plants (Table 1) were subjected to shade drying and after powdered and passed through $20 \#$ sieve. Those 
Table 1: Authentication of herbs present in the PHF

\begin{tabular}{llll}
\hline Herbs & Family & Code & Part used \\
\hline Cassia auriculata L. & Caesalpiniaceae & CA & Flower \\
Cinnamomum tamala & Lauraceae & CT & Leaves \\
Ficus benghalensis L. & Moraceae & RB & Root bark \\
Mangifera indica L. & Anacardiaceae & MI & PG/CT/L-003 \\
Trichosanthes dioica & Cucurbitaceae & TD & PG/FB/B-003 \\
\hline
\end{tabular}

PHF: Polyherbal formulation

prepared plant powder materials were individually macerated with distilled water (1:10), and all the aqueous plant extracts were imperiled to lyophilization. Lyophilized extracts were store at airtight container and store in a dark, cool place for further use.

\section{Experimental animals}

The animal experimentation was carried out using either sex of adult Wistar albino rats $(180 \pm 10 \mathrm{~g})$. Before the experiment, all the animals were placed in-house in polyacrylic cages with dark and light $24 \mathrm{~h}$ cycle at ambient room temperature with free access of water and rodent pellets diet. The animal experimentation protocol was approved by IAEC of Rajiv Gandhi Institute of Pharmacy and experimentation was carried out as per the CPCSEA guidelines. Preliminary screening for phytochemical $1 \mathrm{~g}$ each of lyophilized plant extracts was dissolved in $100 \mathrm{ml}$ of distilled water and subjected to qualitative analysis of phytochemicals such as alkaloids, tannins, glycosides, flavonoids, phenolic compounds, and saponins as per standard chemical methods [2]

\section{Development of PHF}

About $1 \mathrm{~g}$ each of lyophilized plant extracts were dissolved in $100 \mathrm{ml}$ of distilled water and subjected to qualitative analysis of phytochemicals such as alkaloids, tannins, glycosides, flavonoids, phenolic compounds, and saponins as per standard chemical methods [2].

\section{Total phenolic content (TPC) determination}

Sample stock preparation was done with 50\% methanol in $100 \mathrm{ml}$ volumetric flask with triplicate maceration of $1 \mathrm{~g}$ PHF in methanol. $1 \mathrm{ml}$ aliquot diluted 10 times with distilled water and later added with $1.5 \mathrm{ml}$ Folin-Ciocalteu's reagent. The solution mixture was incubated for $5 \mathrm{~min}$ at room temperature. After incubation solution mixture was further added with $4 \mathrm{ml}$ of $20 \% \mathrm{Na}_{2} \mathrm{CO}_{3}(\mathrm{w} / \mathrm{w})$ and make up the volume up to $25 \mathrm{ml}$ with distilled water. The reaction mixture was agitated and keeps for $30 \mathrm{~min}$ at room temperature. The absorbance was measured at $765 \mathrm{~nm}$ in UV spectrophotometer against the blank. Similarly, standard gallic acid stock sample also prepared with methanol $(100 \mu \mathrm{g} / \mathrm{ml})$, and various dilutions concentrations were prepared such as $6.25,12.5,25$, and $50 \mu \mathrm{g} / \mathrm{ml}$ and standard gallic acid curve also been plotted against the absorbance at $765 \mathrm{~nm}$ by UV spectrophotometer against the blank [14].

$$
\% \mathrm{TPC}(\mathrm{w} / \mathrm{w})=\mathrm{GAE} \times \mathrm{V} \times \mathrm{D} \times 10-6 \times 100 / \mathrm{W} \text {, }
$$

GAE - Gallic acid equivalent $(\mu \mathrm{g} / \mathrm{ml}), \mathrm{V}$ - total volume of sample $(\mathrm{ml})$, $\mathrm{D}$ - Dilution factor, $\mathrm{W}$ - Sample weight $(\mathrm{g})$.

\section{Total flavonoid content (TFC) determination}

Standard rutin stock solution is prepared $(100 \mu \mathrm{g} / \mathrm{ml})$ using $80 \%$ methanol and various dilute concentrations such as 10, 20, 40, 80, and $100 \mu \mathrm{g} / \mathrm{ml}$ been prepared. Each $0.5 \mathrm{ml}$ standard rutin dilution is added with $1.5 \mathrm{ml} 95 \%$ methanol, $0.1 \mathrm{ml}$ of $10 \%$ aluminum chloride, $0.1 \mathrm{ml}$ $1 \mathrm{M}$ potassium acetate, and $2.8 \mathrm{ml}$ of distilled water and incubated for $30 \mathrm{~min}$ at room temperature. Absorbance measured at $415 \mathrm{~nm}$ using UV spectrophotometer against the blank. Similarly, $1 \mathrm{~g}$ of PHF dissolved separately in $25 \mathrm{ml}$ of $80 \%$ methanol for determination of flavonoids content as described above [14].

\section{\%total flavonoids content $(\mathrm{w} / \mathrm{w})=\mathrm{RE} \times \mathrm{V} \times \mathrm{D} \times 10-6 \times 100 / \mathrm{W}$}

$\mathrm{RE}$ - rutin equivalent $(\mu \mathrm{g} / \mathrm{ml}), \mathrm{V}$ - total volume of sample (ml), D - dilution factor, $\mathrm{W}$ - sample weight ( $\mathrm{g}$ ).

\section{Study for acute toxicity}

The study was performed as per the OECD guideline-425. Experimental Wister rats were fasted overnight before the study. Fasted animals were divided into four groups of six animals each. Individual groups were administered orally with PHF dose from 250, 500, and 1000 and 2000, 4000 , and $5000 \mathrm{mg} / \mathrm{kg} \mathrm{b.w}$, respectively. All the groups of animals were initially observed for $1 \mathrm{~h}$ and periodically for next $24 \mathrm{~h}$ up to 14 days for any gross behavioral changes such as drowsiness, restlessness, writhing, convulsions, symptoms of toxicity, and mortality.

Oral glucose tolerance test (OGTT) on normal and diabetic animals Experimental animals were randomly selected and grouped into three of six each. The Groups I and II were treated with the vehicle carboxymethylcellulose solution $(0.5 \% \mathrm{w} / \mathrm{v}$ in normal saline) and PHF (500 mg/kg b.w), respectively. Whereas Group III was treated with standard glibenclamide ( $1 \mathrm{mg} / \mathrm{kg}$ b.w), Groups II and III were administered with PHF and glibenclamide and after $30 \mathrm{~min}$ all the experimental animals including Group I was fed orally with $2 \mathrm{~g} / \mathrm{kg}$ of glucose solution. After a particular time interval, namely $0,30,60,90$, and $120 \mathrm{~min}$, blood was withdrawn from the tail vein. The estimation of blood glucose level was measured by Accu-Chek, Roche Diabetes Care India [15]

\section{Hypoglycemic activity in STZ-induced diabetic rats}

Experimental diabetes was induced by $0.5 \mathrm{ml} / \mathrm{kg}$ b.w IP injection of freshly prepared STZ (50 mg/kg b.w. in $0.1 \mathrm{M}$ citrate buffer at $\mathrm{pH} 4.5$ ) in overnight fasted animals [16]. After $24 \mathrm{~h}$, the STZ treated animals were given with glucose solution $(5 \% \mathrm{w} / \mathrm{v})$ at the dose of $2 \mathrm{ml} / \mathrm{kg}$ bw to prevent the mortality due to hypoglycemic shock. The induced rats with fasting blood glucose $>300 \mathrm{mg} / \mathrm{dl}$ were considered as diabetics and taken for hypoglycemic activity. Experimental animals (male Wistar rats) were divided into three groups with six animals each. Groups II-IV were designated as diabetic control. Glibenclamide ( $5 \mathrm{mg} / \mathrm{kg} \mathrm{bw}$ ) treated and PHF $(500 \mathrm{mg} / \mathrm{kg}$, bw) treated groups. Another six animals were taken as normal control without STZ as Group I. Except the Groups I and II; all other groups were treated with standard glibenclamide and PHF (suspended in 1\% w/v carboxymethylcellulose) through oral gavage for 21 consecutive days. During this time period blood, samples were been taken through the retro-orbital route of the animal in a specific time interval such as 0 day, $7^{\text {th }}$ day, $14^{\text {th }}$ day, and $21^{\text {st }}$ day for estimation of blood glucose level. The estimations were done by Chem Biochemistry Analyzer (AN Biotech, India). Body weight of experimental animals also measured in this specified time intervals.

\section{Blood collection and harvestmen of organs}

Blood collection and harvesting of organs were taken place after a $21^{\text {st }}$ day of experimentation. The animals were sacrificed by ether anaesthetization, and an aliquot of blood $(5 \mathrm{ml})$ was collected from a jugular vein in plain and ethylenediaminetetraacetic acid tubes tube and centrifuged at $1282 \mathrm{~g} \times 5 \mathrm{~min}$. After centrifugation, the serum was separated with Pasteur Pipette in plain tubes and subjected for biochemical estimations [17]. Meanwhile, the rats were dissected, and the organs were isolated such as whole liver, pancreas, and two kidneys. After isolation, the specimens are freed from extracellular fats and deposited in formalin solution for further histopathological investigations.

Lipid profile and total protein estimations

The entire estimations of lipid profiles such as total cholesterol, triglycerides, high-density lipoprotein (HDL)-cholesterol, and low- 
density lipoprotein (LDL)-cholesterol along with total protein were screened with the standard procedure using Chem Biochemistry Analyzer (AN Biotech, India) [22].

\section{Liver and kidney function tests}

Estimation of serum creatinine [19], urea [20], uric acid [21], total bilirubin [22], albumin [23], and alkaline phosphatase (ALP) [24], gamma-glutamyltransferase (GGT) [25], aspartate transaminases (AST), and alanine transaminases (ALT) [26] was carried out using standard procedure.

\section{Histopathological analysis}

The preserved organs were further taken to the microscopic slide with egg albumin and allowed to dry. After dehydration, the tissues were subjected to xylene solution for 15-20 min for further cleaning. Clean tissues were put in paraffin infiltration in the automatic tissue processing unit, and tissue blocks were prepared. The thin sections $(5 \mu \mathrm{m})$ of tissue were obtained using microtome. The sections were further taken to the microscopic slide with egg albumin and allowed to dry. Finally, staining of the sections done with an acidic and basic dye, namely Eosin and hematoxylin, respectively $[27,28]$.

\section{Statistical analysis}

The experimental data produced as mean \pm SEM. All statistical significance were found in groups were established by one-way analysis of variance (ANOVA) followed by Dunnett's $t$-test post hoc test. $\mathrm{p}<0.5$ was considered significant [29].

\section{RESULTS}

Preliminary screening of phytochemicals

Preliminary phytochemical screening of PHF indicates the presence of phytochemicals such as alkaloids, glycosides, tannins, flavonoids, and phenolics in the mixture.

\section{TPC and TFC of PHF}

In this PHF, TPC and TFC were found to be $81.01 \pm 15 \mathrm{GE} / \mathrm{g}$ and $10.16 \pm 11$ $\mathrm{RE} / \mathrm{g}$ (Table 2), respectively.

Table 2: TPC and TFC of PHF

\begin{tabular}{ll}
\hline TPC $^{\mathrm{a}}$ & $81.01 \pm 1.50$ \\
TFC $^{\mathrm{b}}$ & $10.16 \pm 1.13$ \\
\hline
\end{tabular}

Values are means \pm SEM of three replicate studies. ${ }^{\mathrm{a}} \mathrm{GE} / \mathrm{g}: \mathrm{Mg}$ gallic acid equivalent, ${ }^{\mathrm{b}} \mathrm{QE} / \mathrm{g}$ : Mg rutin equivalent. TPC: Total phenolic content, TFC: Total flavonoid content, PHF: Poly-herbal formulation

\section{Study of acute toxicity}

PHF was found to be non-toxic at the optimum dose of $5000 \mathrm{mg} / \mathrm{kg} \mathrm{bw}$. There was no evidence of behavioral change in the animals observed even no mortality as well. Any other symptoms such as breathing, sensory nervous system, gastrointestinal effects, or toxicity also were found absent in all experimental animals during the observational period indicating the high margin of safety of PHF.

\section{OGTT on normal and experimental rats}

There was a significant $(\mathrm{p}<0.05)$ reduction of blood plasma glucose level in PHF-treated group and glibenclamide $(0.25 \mathrm{mg} / \mathrm{kg})$-treated group compared to normal control (Table 3) whereas no significant change observed in normal control animals during the period of study.

\section{Hypoglycemic activity of PHF in diabetic-induced rats}

PHF-treated group has been shown a significant reduction about $91.83 \pm 2.96 \mathrm{mg} / \mathrm{dl}$ of blood sugar compared to the diabetic control group, whereas $123.83 \pm 2.11 \mathrm{mg} / \mathrm{dl}$ found in glibenclamide-treated group. These results indicate the normalization of blood sugar level with PHF in diabetic rats (Tables 4 and 5) as compared to normal control group $(90.83 \pm 1.77 \mathrm{mg} / \mathrm{dl})$ of animals.

\section{Total protein and lipid profile test}

The automatic analyzer has been employed for the screening of total cholesterol, triglycerides, HDL-cholesterol, total protein, LDL, and VLDL, respectively, in blood serum of experimental animals (Table 6) [18].

\section{Liver and kidney function tests}

The concentrations of creatinine [19], urea [20], total bilirubin [22], albumin [23] as well as the activities of ALP [24], GGT [25] and AST, ALT, and BUN [26] were determined in the serum (Table 7).

\section{Histopathologic analysis}

Kidney

The histological sections showed intact cellular architecture and normal cellularity in the glomerulus. The normal group showed the intact tubules (Fig. 1a) and blood vessels. Interstitium showed to be unremarkable. Most of the tubules in the diabetic group showed degenerative changes (Fig. 1b) with dispersed interstitial inflammatory mononuclear infiltration. The glibenclamide treated groups showed moderate degenerative changes in few tubules (Fig. 1c), whereas minimal degenerative tubules changes (Fig. 1d) found in the PHF treated group.

Table 3: OGTT

\begin{tabular}{lllllll}
\hline Groups & Blood glucose levels(mg/dl) & & & & \\
\cline { 2 - 7 } & Treatments & 0min & 30min & 60min & 90min & 120min \\
\hline Group1 & Normal control & $92.28 \pm 2.57$ & $143.33 \pm 2.08$ & $134.33 \pm 2.99$ & $120.19 \pm 2.99$ \\
Group2 & PHF(500 mg/kg) & $92.76 \pm 3.62$ & $127.34 \pm 1.96$ & $116.45 \pm 4.25$ & $103.22 \pm 3.23^{*}$ & $95.66 \pm 2.06$ \\
Group4 & Glibenclamide $(0.25 \mathrm{mg} / \mathrm{kg})$ & $91.58 \pm 2.96$ & $119.21 \pm 2.11^{* *}$ & $102.65 \pm 3.02^{* *}$ & $96.35 \pm 2.96^{* *}$ & $90.54 \pm 3.59$ \\
\hline
\end{tabular}

Values are mean $\pm \mathrm{SEM}, \mathrm{n}=6,{ }^{*} \mathrm{p}<0.05,{ }^{* *} \mathrm{p}<0.01$ compared to normal control group. One-way ANOVA followed by Dunnett's multiple comparison test, OGTT: Oral glucose tolerance test, PHF: Poly-herbal formulation

Table 4: Blood glucose level in normal and experimental animals

\begin{tabular}{|c|c|c|c|c|}
\hline \multirow{2}{*}{$\begin{array}{l}\text { Biochemical } \\
\text { Parameters }\end{array}$} & \multicolumn{4}{|c|}{ Blood sugar(mg/dl) } \\
\hline & 0Day & $7^{\text {th }}$ Day & $14^{\text {th }}$ Day & $21^{\text {st }}$ Day \\
\hline Normal control & $90.83 \pm 3.93$ & $95.33 \pm 3.09$ & $92.66 \pm 4.06$ & $90.83 \pm 1.77$ \\
\hline Diabetic control & $370.00 \pm 3.00$ & $390.50 \pm 3.50$ & $403.16 \pm 4.94$ & $415.33 \pm 3.54$ \\
\hline Diabetic+glibenclamide & $371.66 \pm 2.68$ & $277.66 \pm 4.42^{* *}$ & $190.66 \pm 2.28^{*}$ & $123.83 \pm 2.11^{*}$ \\
\hline Diabetic+PHF & $364.16 \pm 4.29 *$ & $272.00 \pm 4.19^{* *}$ & $141.83 \pm 3.80^{* *}$ & $91.83 \pm 2.96^{* *}$ \\
\hline
\end{tabular}

All values are expressed as mean \pm S.E.M(n=6). ${ }^{*} \mathrm{p}<0.05,{ }^{* *} \mathrm{p}<0.01$ as compared to diabetic control. One-way ANOVA followed by Dunnett's multiple comparison test, PHF: Poly-herbal formulation 


\section{Pancreas}

The histological study reveals the septal separation of pancreatic lobules. Few of the lobules showed small areas of light-staining islets of Langerhans. Around $65 \%$ of small beta cells in central islet cells were been found in normal control groups (Fig. 1e [long-arrow]), and $30 \%$ large alpha-cells seen in the periphery (Fig. 1e [short-arrow]). In diabetic control section, most of the beta cells show degenerative changes with $40 \%$ beta-cell in center of islet cells (Fig. 1f [long-arrow]), while the periphery comprises 55\% large alpha-cells (Fig. 1f [shortarrow]). The glibenclamide-treated animal pancreatic cells showed some degenerative changes of the beta cells. The center of islet cells consists of $50 \%$ small beta-cells (Fig. 1g [long-arrow]), while the periphery comprises $45 \%$ large alpha-cells (Fig. 1g [short-arrow]). In PHF-treated section studied shows the center of islet cells consist of $65 \%$ small beta-cells (Fig. 1h [long-arrow]), while the periphery comprises 30\% large alpha-cells (Fig. 1h, [short arrow]). Intervening these cells is seen vascular spaces in all the sections.

\section{Liver}

All the sections showed liver parenchyma with intact architecture, the periportal, perivenular, and mid zonal hepatocytes appear unremarkable. In Normal control, the central veins and Sinusoids appear unremarkable (Fig. 1i). Sinusoids appear unremarkable. Whereas in diabetic control Section showed the periportal region had dense mononuclear inflammatory infiltration (Fig. 1j). Standard glibenclamide-treated group section reviled the unchanged central veins (Fig. 1k) and sinusoids. In the case of PHF-treated groups section

Table 5: Change of body weight in normal and experimental rats

\begin{tabular}{lllll}
\hline Groups & \multicolumn{4}{l}{ Body weight(g) } \\
\cline { 2 - 5 } & 0Day & $\mathbf{7}^{\text {th }}$ Day & $\mathbf{1 4}^{\text {th }}$ Day & $\mathbf{2 1}^{\text {st }}$ Day \\
\hline Normal control & $181 \pm 2.8$ & $182 \pm 3.8$ & $184 \pm 2.0$ & $186 \pm 3.1$ \\
Diabetic control & $178 \pm 3.7$ & $174 \pm 3.2$ & $170 \pm 2.9$ & $168 \pm 3.4$ \\
Diabetic+glibenclamide & $190 \pm 2.1$ & $190 \pm 2.2^{* *}$ & $194 \pm 3.1^{* *}$ & $196 \pm 1.6^{* *}$ \\
Diabetic+PHF & $180 \pm 1.9$ & $182 \pm 3.1^{*}$ & $185 \pm 2.6^{*}$ & $189 \pm 3.2^{*}$ \\
\hline
\end{tabular}

All values are expressed as mean \pm S.E.M $(n=6) .{ }^{*} \mathrm{p}<0.05,{ }^{* *} \mathrm{p}<0.01$ as compared to diabetic control. One-way ANOVA followed by Dunnett's multiple comparison test. PHF: Poly-herbal formulation studied shows that the periportal region shows moderate mononuclear inflammatory infiltration (Fig. 11). The central veins and sinusoids appear unremarkable as like all the sections.

\section{DISCUSSION}

The concept of poly-pharmacy has been practicing since from ancient time. The proven examples are listed in various Ayurveda literature. This trend also recognized by the WHO in some clinical aliment like diabetes which is a metabolic disorder associated with polydipsia and polyphagia.

Lyophilized aqueous plant extracts were been used to formulate the PHF to minimize the residual solvent toxicity. All those used herbs were also proven for their antioxidant properties. The PHF consisting of various important phytoconstituents such as alkaloids, tannins, glycosides, flavonoids, and phenolic compounds, where later two are natural antioxidants, reported to significantly increase superoxide dismutase (SOD), glutathione and catalase activities eventually promoters the expression of SOD, catalase, and glutathione [27]. The endothelial dysfunctions due to hyperlipidemia, hyperinsulinemia, and hyperglycemia are the result of oxidative stress [28], which leads to diabetes mellitus. The reduction of antioxidant enzymes, inactivation of enzymes and lipid peroxidation cause cell death while free radicals get excess produces. The presence of a significant amount of phenolic and flavonoids contents makes this formulation potent scavenging and antioxidants in biological systems. As per existing studies on diabetes mellitus, it has been observed that the progression of this disorder leads to boosting the free radicals and potentially decrease the cellular antioxidant capacity leads to oxidative stress even both insulin dependent and independent diabetes mellitus [29]. The tolerability with high dose $(5000 \mathrm{mg} /$ $\mathrm{kg}$ b.w) in experimental animals reflects the effect of altered carbohydrate metabolism during the post-glucose administration. The prolonged hypoglycemic study evident significant decrease in blood glucose level may be due to the synergistic effect of all bioactive phytochemicals in various bio levels. The results also correlate with the study carried by El-Baz1 et al., 2017, on Haematococcus pluvialis where the bioactive principles found were the flavonoids [27]. Rats orally treated with the PHF at a dose level of $500 \mathrm{mg} / \mathrm{kg}$ of b. w were found to have significantly reduced activities of these enzymes, thus indicating less damage to hepatocytes. Similar action was also

Table 6: Analysis of serum lipid profile and total protein

\begin{tabular}{llll}
\hline Biochemical Parameters & Normal control & Diabetic control & Diabetic+Glibenclamide \\
\hline Cholesterol(mg/dl) & $53.57 \pm 2.95$ & $63.01 \pm 2.46$ & $55.82 \pm 4.59$ \\
Triglyceride(mg/dl) & $30.98 \pm 2.81$ & $48.79 \pm 2.89$ & $32.70 \pm 1.90^{*}$ \\
HDLc(mg/dl) & $17.75 \pm 0.35$ & $23.11 \pm 0.44$ & $20.25 \pm 1.47$ \\
Total protein & $07.21 \pm 0.12$ & $07.27 \pm 0.30$ & $07.22 \pm 0.26$ \\
LDL(mg/dl) & $07.03 \pm 1.85$ & $15.91 \pm 1.50$ & $05.91 \pm 2.63^{*}$ \\
VLDL(mg/dl) & $06.19 \pm 0.56$ & $09.75 \pm 0.58$ & $06.54 \pm 0.38^{*}$ \\
\hline
\end{tabular}

All values are expressed as mean \pm S.E.M(n=6). HDLc: High-density lipoprotein-cholesterol, LDL: Low-density lipoprotein, VLDL: Very low-density lipoprotein, ${ }^{*} \mathrm{p}<0.05$,

${ }^{* *} \mathrm{p}<0.01$ as compared to diabetic control. One-way ANOVA followed by Dunnett's multiple comparison test

Table 7: Liver and kidney function tests

\begin{tabular}{llll}
\hline Biochemical Parameters & Normal control & Diabetic control & Diabetic+glibenclamide \\
\hline Creatinine(mg/dl) & $0.536 \pm 0.01$ & $0.606 \pm 0.03$ & $0.556 \pm 0.01$ \\
Urea(mg/dl) & $42.61 \pm 2.80$ & $59.44 \pm 1.79$ & $46.53 \pm 3.15^{*}$ \\
Total bilirubin( $\mu$ mol/l) & $0.24 \pm 0.08$ & $0.228 \pm 0.08$ & $0.216 \pm 0.084$ \\
Albumin(g/dl) & $3.32 \pm 0.13$ & $3.15 \pm 0.34$ & $3.22 \pm 0.10$ \\
ALP(U/L) & $261.83 \pm 4.23$ & $568.83 \pm 4.27$ & $280.86 \pm 3.99 *$ \\
GGT(U/L) & $2.01 \pm 1.56$ & $8.04 \pm 5.85$ & $2.95 \pm 2.71^{*}$ \\
AST(U/L) & $155.8 \pm 4.14$ & $263.50 \pm 3.91$ & $159.93 \pm 4.63^{*}$ \\
ALT(U/L) & $66.05 \pm 2.90$ & $131.96 \pm 3.86$ & $86.4 \pm 4.31$ \\
BUN(mg/dl) & $17.57 \pm 0.35$ & $27.77 \pm 0.25$ & $24.03 \pm 0.13^{* *}$ \\
\hline
\end{tabular}

All values are expressed as mean \pm S.E.M(n=6). ALP: Alkaline phosphatase, GGT: Gamma-glutamyl transferase, AST: Aspartate transaminases, ALT: Alanine transaminases, ${ }^{*} \mathrm{p}<0.05,{ }^{* *} \mathrm{p}<0.01$ as compared to diabetic control. One-way ANOVA followed by Dunnett's multiple comparison test 

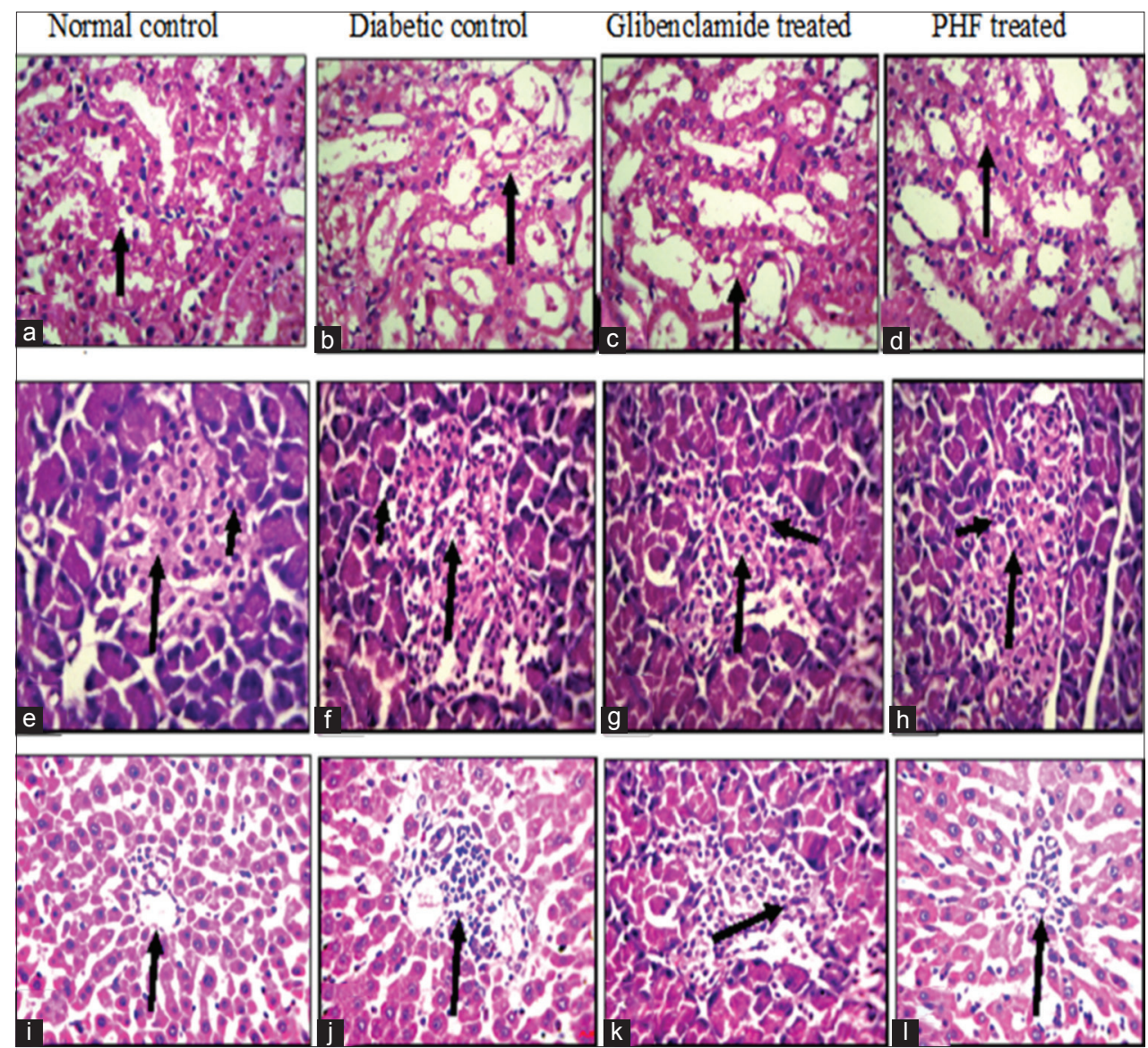

Fig. 1: Histopathological analysis of organs (kidney [a-d], pancreas [e-h], and liver [i-1]) H and E, $\times 400$

been reported by Talha et al., 2015, in their study on the effects of the ethanolic extract of Alocasia indica rhizomes [30]. STZ-induced diabetic rats are associated with hyperlipidemia and increased levels of serum creatinine which all significantly controlled by PHF. The lowering of these lipid substances and serum creatinine in the blood of treated rats is presumed mainly to be a manifestation of lowering of blood glucose level. Low protein degradation found in PHF treated animals which leads to high serum protein concentration. Due to the reduction in lowering of glucose levels thus sparing the body fat and muscle protein which otherwise are utilized in diabetic rats probably indicates the elevation of body weight among the rats administered with PHF.

\section{CONCLUSION}

The common symptoms of diabetes, that includes polyphagia, polydipsia, and weight loss, were found to be lessened by the PHF dose level of $500 \mathrm{mg} / \mathrm{kg}$ of b. $\mathrm{w}$ in diabetic rats. Along with the significant reduction of fasting glucose level and lipid profile of diabetic rats were the outcome of this study. The PHF was found significantly decreasing the activities of liver enzymes and ALP in diabetic rats. The histopathological investigation along with the biochemical evaluations strongly suggests the hypoglycemic potential of PHF. The results also indicate the effect of PHF on the regeneration of pancreatic $\beta$-cells leading to blood glucose regulation in the body.

\section{AUTHORS' CONTRIBUTIONS}

All the authors contribute the same contributions to this research.

\section{CONFLICTS OF INTEREST}

The authors declare that they have no conflicts of interest regarding the publication of this paper.

\section{REFERENCES}

1. Adeghate E, Schattner P, Dunn E. An update on the etiology and epidemiology of diabetes mellitus. Ann N Y Acad Sci 2006;1084:1-29.

2. Petchi RR, Parasuraman S, Vijaya C. Antidiabetic and antihyperlipidemic effects of an ethanolic extract of the whole plant of Tridax procumbens (Linn.) in streptozotocin-induced diabetic rats. J Basic Clin Pharm 2013;4:88-92.

3. Chorgade MS. Drug Discovery and Development. Vol. 2. Hoboken, New Jersey: John Wiley and Sons Inc.; 2007.

4. Surana SJ, Gokhale SB, Jadhav RB, Sawant RL, Wadekar JB. Antihyperglycemic activity of various fractions of Cassia auriculata Linn. In alloxan diabetic rats. Indian J Pharm Sci 2008;70:227-9.

5. Pari L, Latha M. Effect of Cassia auriculata flowers on blood sugar levels, serum and tissue lipids in streptozotocin diabetic rats. Singapore Med J 2002;43:617-21

6. Luka CD, Mohammed A. Evaluation of the antidiabetic property of aqueous extract of Mangifera indica leaf on normal and alloxaninduced diabetic rats. J Nat Prod Plant Resour 2012;2:239-43.

7. Amrita B, Liakot A, Masfida A, Begum R. Studies on the antidiabetic effects of Mangifera indica stem-barks and leaves on non-diabetic, Type 1 and Type 2 diabetic model rats. Bangladesh J Pharmacol 2009; 4:110-4

8. Gayathri M, Kannabiran K. Antidiabetic and ameliorative potential of Ficus bengalensis bark extract in streptozotocin induced diabetic rats. Indian J Clin Biochem 2008;23:394-400.

9. Venkanna BB, Prabhu KM, Murthy PS. Studies on the hypoglycaemic activity of the bark of Ficus bengalensis employing alloxan recovered rabbits. Diabetes Bull 1987;7:105-8.

10. Chakraborty U, Das H. Antidiabetic and antioxidant activities of Cinnamomum tamala leaf extracts in stz-treated diabetic rats. Global J Biotec Biochem 2010;5:12-8.

11. Shradha B, Sisodia SS. Assessment of antidiabetic potential of Cinnamomum tamala leaves extract in streptozotocin induced diabetic rats. Ind J Pharmacol 2011;43:582-5.

12. Rai PK, Jaiswal D, Rai DK, Sharma B, Watal G. Effect of water extract of Trichosanthes dioica fruits in streptozotocin induced diabetic rats. 
Ind J Clin Biochem 2008;23:387-90.

13. Shalini A, Bairy KL, Meharban A, Punita IS. Hypoglycemic effect of aqueous extract of Trichosanthes dioica in normal and diabetic rats. Int J Diab Ctries 2010;30:38-2.

14. Singleton VL, Rossi JA. Colorimetry of total phenolics with phosphomolybdic phoshotungstic acid reagents. Am J Enol Vitic 1965;16:144-8.

15. Ramesh C, Prameela rani A. In vivo and in vitro evaluation of Tephrosia calophylla for anti-diabetic properties. Int J Pharm Pharm Sci 2018;10:138-4.

16. Annadurai T, Muralidharan AR, Joseph T, Hsu MJ, Thomas PA, Geraldine $\mathrm{P}$, et al. Antihyperglycemic and antioxidant effects of a flavanone, naringenin, in streptozotocin-nicotinamide-induced experimental diabetic rats. J Physiol Biochem 2012;68:307-18.

17. Parasuraman S, Raveendran R, Kesavan R. Blood sample collection in small laboratory animals. J Pharmacol Pharmacother 2010;1:87-93.

18. Henry RJ, Cannon DC, Winkleman JW. Clinical Chemistry, Principles and Techniques. $2^{\text {nd }}$ ed. London, UK: Harper and Row; 1974.

19. Owen JA, Iggo B, Scandrett FJ, Stewart CP. The determination of creatinine in plasma or serum, and in urine; a critical examination. Biochem J 1954;58:426-37.

20. Marsh WH, Fingerhut B, Miller H. Automated and manual direct methods for the determination of blood urea. Clin Chem 1965;11:624-7.

21. Tietz NW. Clinical Guide to laboratory Tests. $3^{\text {rd }}$ ed. Philadelphia, PA, USA: WB Saunders; 1995
22. Malloy HT, Evelyn KA. The determination of bilirubin with the photoelectric colorimeter. J Biol Chem 1937;119:481.

23. Spencer K, Price CP. Influence of reagent quality and reaction conditions on the determination of serum albumin by the bromcresol green dye-binding method. Ann Clin Biochem 1977;14:105-15.

24. Wright PJ, Leathwood PD, Plummer DT. Enzymes in rat urine: Alkaline phosphatase. Enzymologia 1972;42:317-27.

25. Szasz G. A kinetic photometric method for serum gamma-glutamyl transpeptidase. Clin Chem 1969;15:124-36.

26. Schmidt E, Schmidt FW. Determination of serum GOT and GPT activities. Enzymol Biolo Clin 1963;3:1-5.

27. El-baz1 KF, Aly FH, Abdo MS, Saad SA. Healing potency of Haematococcus pluvialis extract for treating Type 2 diabetes in rats. Int J Pharm Pharm Sci 2017;9:192-8.

28. Ozbek H, Acikara OB, Keskin I, Kirmizi NI, Ozbilgin S, Oz BE, et al. Evaluation of hepatoprotective and antidiabetic activity of Alchemilla mollis. Biomed Pharmacother 2017;86:172-6.

29. Sabu MC, Smitha K, Kuttan R. Anti-diabetic activity of green tea polyphenols and their role in reducing oxidative stress in experimental diabetes. J Ethnopharmacol 2002;83:109-16.

30. Talha J, Saumya A, Mehnaz K. Antidiabetic and antihyperlipidemic effcets of the ethanolic extract of Alocasia indica rhizomes in high fat diet/streptozotocin and streptozotocin/nicotinamide-induced Type 2 diabetic rats. Asian J Pharm Clin Res 2015;8:58-2. 